Research Article

\title{
Electrochemical Determination of Uric Acid in Urine by Using Zeolite Imidazolate Framework-11 Modified Electrode
}

\author{
Tran Si Thanh, ${ }^{1,2}$ Phan Tu Qui, ${ }^{3}$ Nguyen Thi Thanh Tu ${ }^{4},{ }^{4}$ Tran Thanh Tam Toan, ${ }^{1}$ \\ Tran Thi Bich Hoa, ${ }^{1}$ Le Van Thanh Son, ${ }^{5}$ Do Mai Nguyen, ${ }^{1}$ Tran Ngoc Tuyen, ${ }^{1}$ \\ and Dinh Quang Khieu $\mathbb{1}^{1}$ \\ ${ }^{1}$ University of Sciences, Hue University, 49000, Vietnam \\ ${ }^{2}$ Dak Nong Department of Education and Training, 65000, Vietnam \\ ${ }^{3}$ University of Tay Nguyen, 64000, Vietnam \\ ${ }^{4}$ Faculty of Technology, Van Lang University, 70000, Vietnam \\ ${ }^{5}$ University of Education and Science, The University of Da Nang, 50000, Vietnam
}

Correspondence should be addressed to Nguyen Thi Thanh Tu; tu.ntt@vlu.edu.vn and Dinh Quang Khieu; dqkhieu@hueuni.edu.vn

Received 3 March 2021; Revised 14 April 2021; Accepted 20 April 2021; Published 17 May 2021

Academic Editor: Thanh-Danh Nguyen

Copyright (C) 2021 Tran Si Thanh et al. This is an open access article distributed under the Creative Commons Attribution License, which permits unrestricted use, distribution, and reproduction in any medium, provided the original work is properly cited.

In the present article, the synthesis of zeolite imidazole framework-11 (ZIF-11) by ultrasonic-assisted hydrothermal process and its application as an electrode modifier for electrochemical determination of uric acid in urine are demonstrated. The obtained materials were characterized by X-ray diffraction (XRD), scanning electron microscopy (SEM), and nitrogen adsorption/desorption isotherms. It was found that the ZIF-11 with rhombic dodecahedron topology and high surface area $\left(1066 \mathrm{~m}^{2} . \mathrm{g}^{-1}\right)$ was synthesized in a certain temperature and found in around $25-40^{\circ} \mathrm{C}$, and other crystalline phases of zinc benzimidazolate deferring from ZIF-11 phase were found in less $25^{\circ} \mathrm{C}$ or higher than $40^{\circ} \mathrm{C}$. The ZIF-11 is stable in the pH range 6-10. The modification of glassy carbon electrode was performed with ZIF-67 using the drop-casting procedure. The present ZIF-11 modified electrode was employed to study the electrochemical behavior of uric acid (UA). UA oxidation is catalyzed by this electrode in aqueous buffer solution (pH 7) with a decrease of $70 \mathrm{mV}$ in overpotential compared to glassy carbon electrode. With the differential pulse-anodic stripping voltammetry (DP-ASV) method, the oxidation current of UA versus its concentration shows good linearity in the range $20-$ $540 \mu \mathrm{M}(R=0.998)$ with a detection limit of $0.48 \mu \mathrm{M}(S / N=3)$. The obtained ZIF-11 modified electrode was applied in the detection of UA content in urine samples, and satisfied results were obtained.

\section{Introduction}

Uric acid ( $\mathrm{UA}, \mathrm{C}_{5} \mathrm{H}_{4} \mathrm{~N}_{4} \mathrm{O}_{3}$ ) is a natural waste product from the digestion of foods that contain purines. This acid is the main final product of purine metabolism. Abnormal UA levels are usually related to various disorders such as gout/arthritis, hyperuricemia, kidney disease, and Lesch-Nyhan syndrome. Hence, the detection of the UA with a facile method is clinically important because it serves as a marker for the determination of the mentioned diseases. For this purpose, various techniques have been used, such as enzymatic system [1], calorimetry [2], fluorescence [3], high-performance liquid chromatography [4], gas chromatography-mass spectrometry [5], and voltammetry [6]. However, these techniques require expensive equipment, sample pretreatment, skill training, harmful solvents, and considerable time, which limit their application. Meanwhile, electrochemical analysis has several advantages over conventional analytical methods in terms of sensitivity, accuracy, easy operation, and low cost. However, a weak point of electrochemical methods is poor selectivity due to the interferences of other electroactive species and high overpotentials for oxidation [7]. To overcome this obstacle, 
much attention has been paid for electrode surface modification with porous materials that have hierarchical structures, such as ordered mesoporous carbon functionalized with ferrocene carboxylic acid [8], uricase/carbon nanotube/carboxymethyl cellulose [9], poly (3,4-ethylene dioxythiophene) doped with graphene oxide [10], mesoporous $\mathrm{Ag} / \mathrm{TiO}_{2}-\mathrm{SnO}_{2}$ on $\mathrm{g}^{-} \mathrm{C}_{3} \mathrm{~N}_{4}$ nanosheets and decorated with a hierarchical core-shell MOF [11], and others.

Zeolite imidazole frameworks are a subclass of metalorganic frameworks (MOFs) with tunable pore size and chemical functionality, associated with extraordinarily thermal and chemical resistance [12]. Zeolite imidazole framework-11 (ZIF-11) comprises $48 \mathrm{Zn}$ (II) ions within a unit cell, and each $\mathrm{Zn}$ (II) ion is tetrahedral-coordinated to the four nitrogen atoms of 4-benzimidazole (bIm). ZIF-11 with rhombic dodecahedron (RHO) topology exhibits larger cages connected through pore apertures and possesses unusual thermal and chemical stability in water and organic solvents [13]. Thanks to these exceptional properties, ZIF-11 is one of the most promising ZIFs [13]. It has several potential applications, such as membrane [14], gas separation [15], catalysis [16], and others. However, the application of ZIF-11 in electrochemistry is limited. To further enhance the electrochemical application, the surface area, pore properties, morphology, and particle size should be improved and controlled by the improvement of the synthesis method. According to our best knowledge, few papers have reported using ZIF-11 as an electrode modifier for electrochemical determination of uric acid in urine.

In the present work, the ZIF-11 was synthesized by ultrasonic-assisted hydrothermal process. The temperature influence on the ZIF-11 phase formation and its stability in aqueous solutions with different $\mathrm{pHs}$ are studied. Besides, the electrochemical determination of uric acid on a glassy carbon electrode modified with ZIF-11 is demonstrated.

\section{Experimental}

2.1. Materials. Zinc acetate dihydrate $\left(\mathrm{Zn}\left(\mathrm{CH}_{3} \mathrm{COO}\right)_{2} \cdot 2 \mathrm{H}_{2} \mathrm{O}\right.$, $>98 \%)$, benzimidazole $\left(\mathrm{C}_{7} \mathrm{H}_{6} \mathrm{~N}_{2}, 98 \%\right)$, uric acid $(>99 \%)$, boric acid $\left(\mathrm{H}_{3} \mathrm{BO}_{3},>99 \%\right)$, acetic acid, $\left(\mathrm{CH}_{3} \mathrm{COOH}, 99.7 \%\right)$, and phosphoric acid $\left(\mathrm{H}_{3} \mathrm{PO}_{4}, 85 \%\right.$ in water) are obtained from Merck. Britton-Robinson buffer (BRB) was prepared by mixing $0.5 \mathrm{M}$ boric acid, $0.5 \mathrm{M}$ acetic acid (99\%), and $0.5 \mathrm{M}$ phosphoric acid (85\%).

2.2. Synthesis of ZIF-11. The synthesis of ZIF-11 was conducted according to reference [17]. Briefly, $3.3 \mathrm{~g}$ of zinc acetate was added to a homogeneous solution composed of $3.6 \mathrm{~g}$ benzimidazole, $144 \mathrm{~g}$ methanol, $138 \mathrm{~g}$ toluene, and $1.7 \mathrm{~g}$ ammonium hydroxide under ultrasonic stirring at a certain temperature $\left(5,15,25,40,60,80\right.$, and $\left.100^{\circ} \mathrm{C}\right)$ for 3 hours. The resultant solids were rinsed with methanol several times and dried overnight at $80^{\circ} \mathrm{C}$ to obtain zinc benzimidazolate.

2.3. Instrument. The crystalline information and morphology of ZIF-11 were obtained from X-ray diffraction (XRD, JED2300 JEOL) and scanning electron microscopy (SEM, JEOL-JSM $5410 \mathrm{LV}$ ) data. Its textural properties were inves-

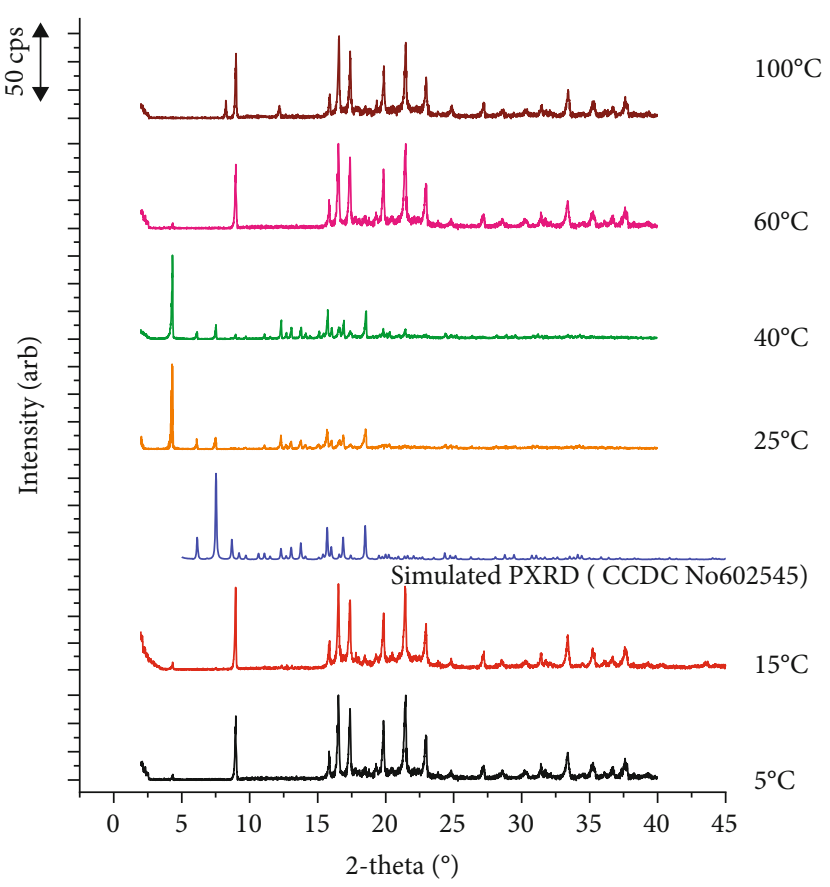

FIGURE 1: XRD patterns of zinc benzylimidazolate synthethesized at $5,15,25,40,60$, and $100^{\circ} \mathrm{C}$.

tigated via nitrogen adsorption-desorption isotherms data (Micromeritics Tristar 3000 at $77 \mathrm{~K}$ ).

A conventional three-electrode system (CPA-HH5 computerized polarography analyzer (Vietnam)) consists of a bare glassy carbon electrode (GCE, $d=2.8 \mathrm{~mm}$ ) or a ZIF-11modified GCE as a working electrode, an $\mathrm{Ag} / \mathrm{AgCl}$ electrode as a reference electrode, and a platinum wire electrode as an auxiliary electrode. High-performance liquid chromatography (HPLC) for uric acid analysis was conducted on a Shimadzu 2030 HPLC system with a UV-Vis detector $(\lambda=275 \mathrm{~nm})$.

2.4. Modification of ZIF-11 and Preparation of Real Samples. The glassy carbon electrode was polished sequentially with $0.05 \mu \mathrm{m} \alpha-\mathrm{Al}_{2} \mathrm{O}_{3}$ until a mirror-smooth surface appeared, washed with distilled water, and sonicated in ethanol for $10 \mathrm{~min}$. The electrode was modified with ZIF-11 by using the drop-casting method. Five microlitres of a mixture containing $1 \mathrm{mg}$ ZIF-11 in $1 \mathrm{~mL}$ methanol were dropped from a microsyringe onto the electrode and dried naturally prior to use. Three human urine samples were obtained from healthy volunteers. Before analysis, the samples were filtered through a $0.2 \mu \mathrm{m}$ filter membrane and diluted five times with $0.1 \mathrm{M}$ BRB solution ( $\mathrm{pH} 7)$ to reduce the matrix interferents. Take $10 \mathrm{~mL}$ of the diluted sample for UA analysis using the DPAVS and HPLC method. For recovery calculation, the filtered urine was spiked with the stock solution of UA, followed by diluted five times with $0.1 \mathrm{BRB}$ solution $\mathrm{pH} 7$, and both DPAVS and HPLC measurements were performed.

2.5. Electrochemical Measurements. The cyclic voltammetry (CV) and DP-DPV measurements were performed in a BRB solution at ambient temperature. In a general procedure, 


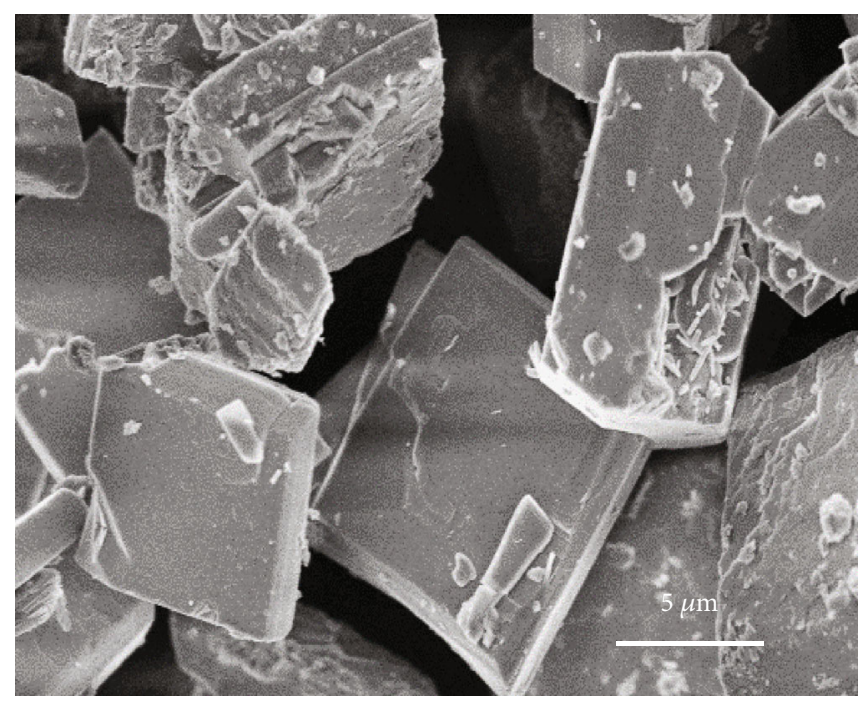

(a)

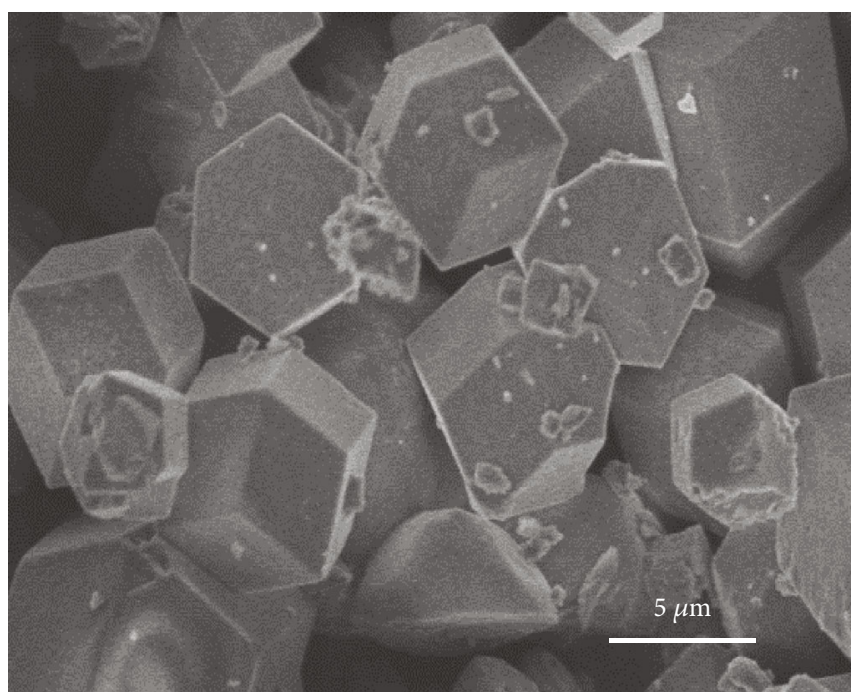

(c)

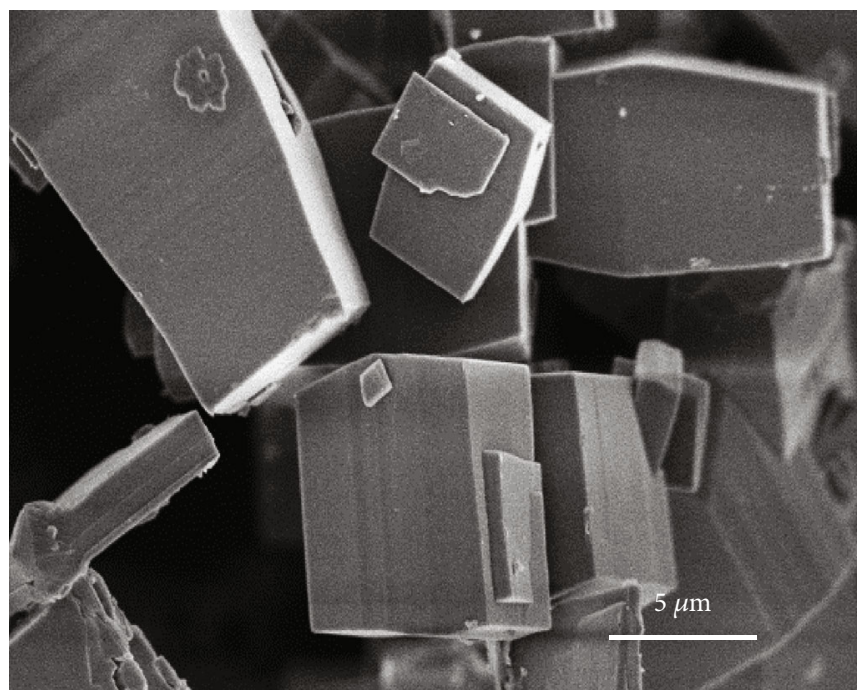

(e)

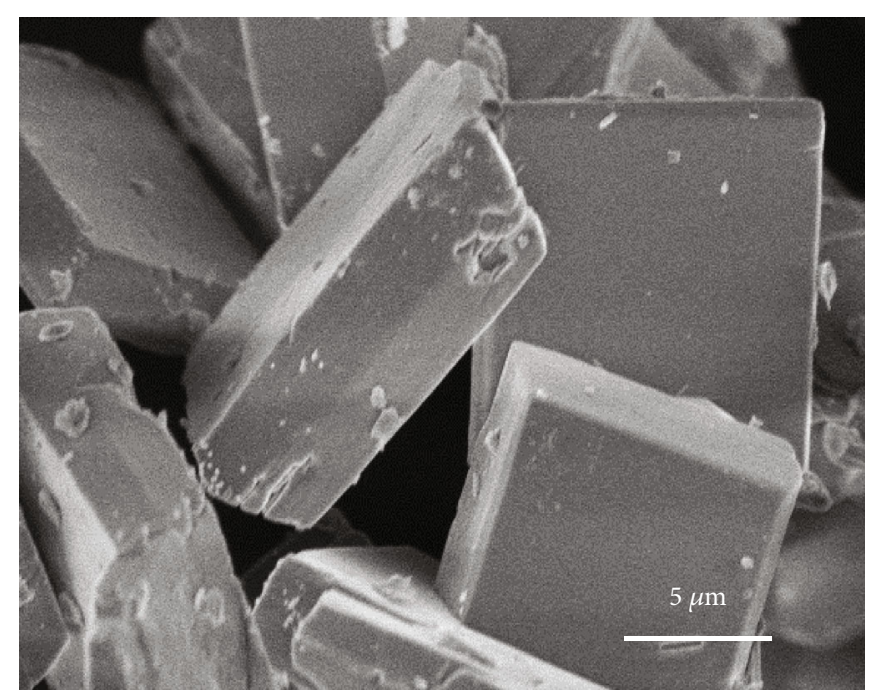

(b)

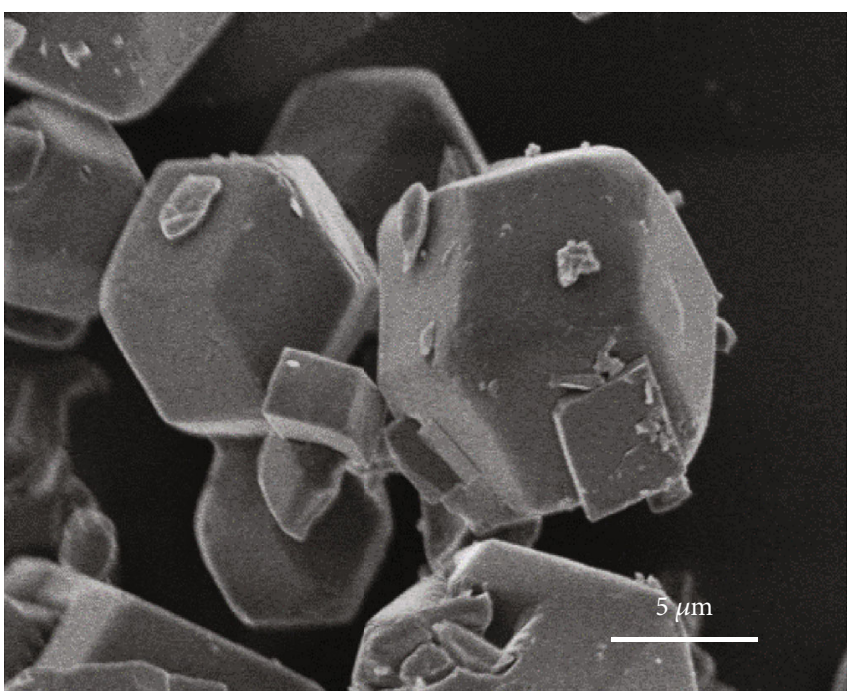

(d)

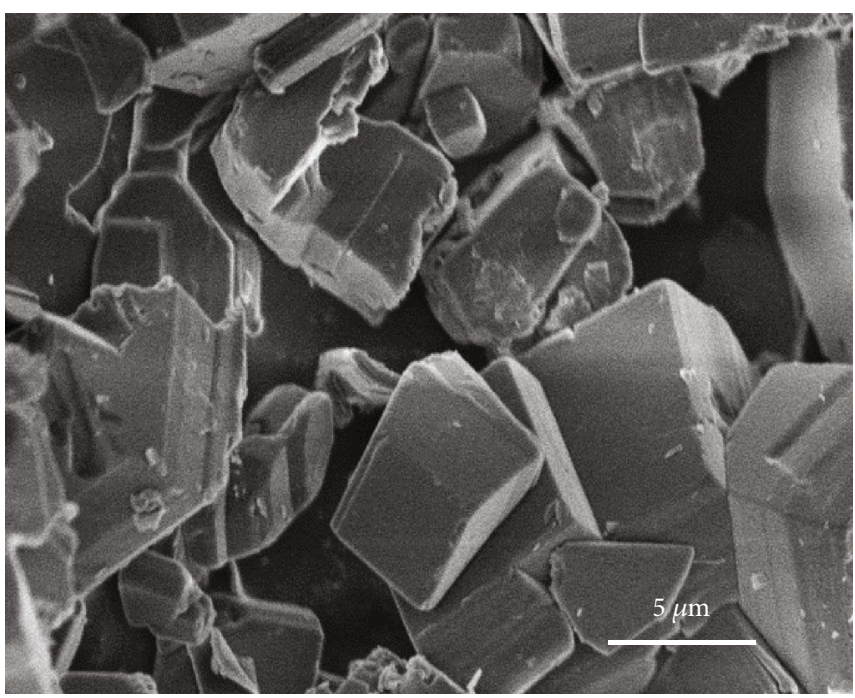

(f)

Figure 2: SEM observations of zinc benzylimidazolate synthesized at (a) $5^{\circ} \mathrm{C}$, (b) $15^{\circ} \mathrm{C}$, (c) $25^{\circ} \mathrm{C}$, (d) $40^{\circ} \mathrm{C}$, (e) $60^{\circ} \mathrm{C}$, and (f) $100^{\circ} \mathrm{C}$. 
TABLE 1: The textural properties of zinc benzimidazolate synthesized at different temperatures.

\begin{tabular}{lccc}
\hline Temperature & Specific surface area $\left(\mathrm{m}^{2} \cdot \mathrm{g}^{-1}\right)$ & Specific micropore surface area $\left(\mathrm{m}^{2} \cdot \mathrm{g}^{-1}\right)$ & Specific external surface area $\left(\mathrm{m}^{2} \cdot \mathrm{g}^{-1}\right)$ \\
\hline $5{ }^{\circ} \mathrm{C}$ & 8 & 0 & 12 \\
$15{ }^{\circ} \mathrm{C}$ & 4.6 & 0 & 6.0 \\
$25{ }^{\circ} \mathrm{C}$ & 1066.8 & 1043.6 & 23.2 \\
$40{ }^{\circ} \mathrm{C}$ & 347.4 & 291.7 & 55.8 \\
$60{ }^{\circ} \mathrm{C}$ & 3.5 & 0 & 4.7 \\
$100^{\circ} \mathrm{C}$ & 2.2 & 0 & 2.1 \\
\hline
\end{tabular}

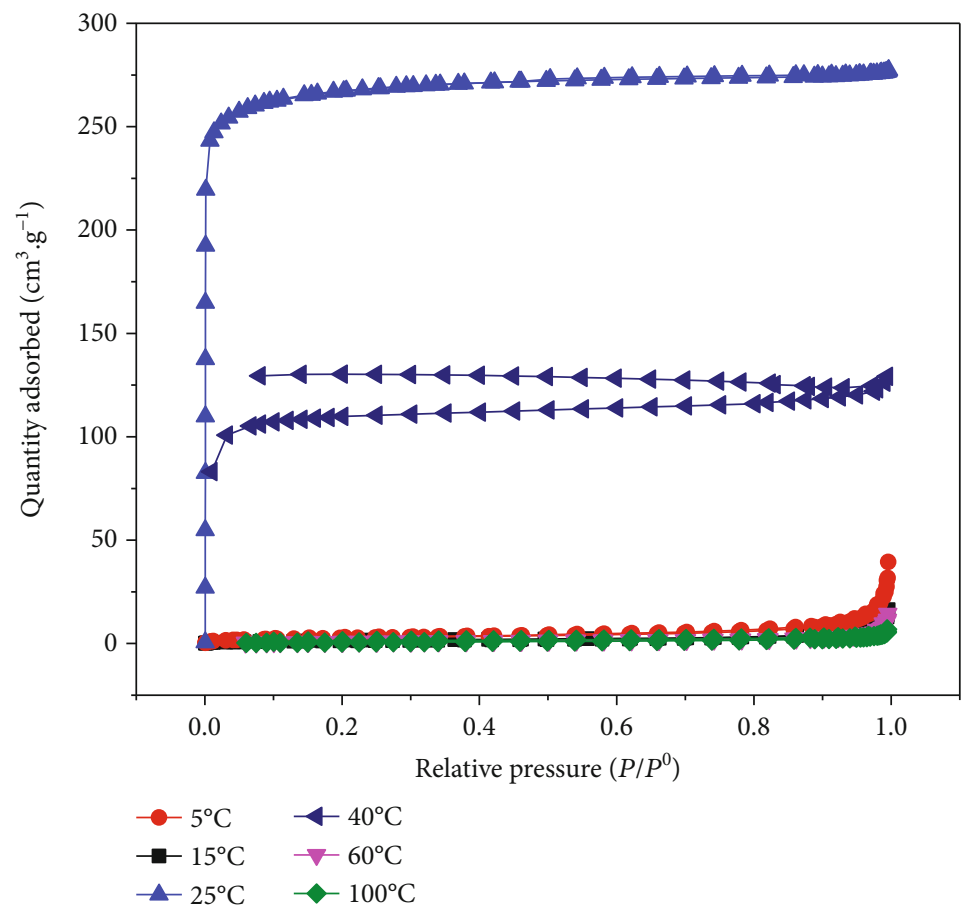

FIGURE 3: Nitrogen adsorption/desorption isotherms of zinc benzimidazolate synthesized at different temperatures.

$1 \mathrm{~mL}$ of BRB containing a UA standard or sample solution was put into a clean electrochemical cell. Before determination, the preconcentration was performed under an open circuit and agitation for $60 \mathrm{~s}$. The $\mathrm{CV}$ measurements were performed from $-0.2 \mathrm{~V}$ to $0.8 \mathrm{~V}$ with a scan rate of $0.125 \mathrm{~V} \cdot \mathrm{s}^{-1}$. The DPV measurements were carried out with a scanning voltage from 0.2 to $0.8 \mathrm{~V}$ with a scan rate of $0.125 \mathrm{mV} \cdot \mathrm{s}^{-1}$, pulse amplitude, $70 \mathrm{mV}$, and quiet time, $5 \mathrm{~s}$. After each measurement, the modified electrodes were washed with distilled water, and they were then put into a blank BRB solution for CV scanning five cycles with the potentials from 0 to $0.8 \mathrm{~V}$ to give a fresh electrode surface.

\section{Result and Discussion}

3.1. Synthesis of ZIF-11. Figure 1 presents the XRD patterns of zinc and the benzimidazolate synthesized at 5, 15, 25, 40, 60 , and $100^{\circ} \mathrm{C}$. It can be seen that reaction temperature substantially affects the crystalline phase of zinc benzimidazolate. The XRD characteristic peaks of ZIF-11 appear in the range of $25-40^{\circ} \mathrm{C}$ and belong to space group $\mathrm{Fm}-3 \mathrm{~m}$, according to the CCDC No. 602545. Outside this range, the crystalline phase of zinc benzimidazolate is different from that of ZIF-11. Hence, the ZIF-11 phase is formed in the temperature range of about $25-40^{\circ} \mathrm{C}$. Since MOFs are considered as "soft porous structure" [18], the phase transition at different synthetic conditions has often been observed [19]. The determination of a specific phase of zinc benzimidazolate outside this temperature is beyond the scope of this work.

The SEM images of ZIFs synthesized at different temperatures are shown in Figure 2. At low temperatures $\left(5-15^{\circ} \mathrm{C}\right)$, cuboids of around $4-6 \mu \mathrm{m}$ are in length form. At a higher temperature $\left(25^{\circ} \mathrm{C}\right), \mathrm{ZIF}-11$ exhibits the RHO topology with regular rhombic dodecahedron particles with $2-4 \mu \mathrm{m}$. The particle size of rhombic dodecahedrons increases to 3-7 $\mu \mathrm{m}$ at $40^{\circ} \mathrm{C}$, and the edges of the rhombic dodecahedrons become less sharp. The particles develop into rectangular cylindrical blocks composed of several layers at $60^{\circ} \mathrm{C}$. At $80^{\circ} \mathrm{C}$ and higher temperatures, ZIF-11 exhibits irregular shapes with stacking layers and cylindrical blocks. 


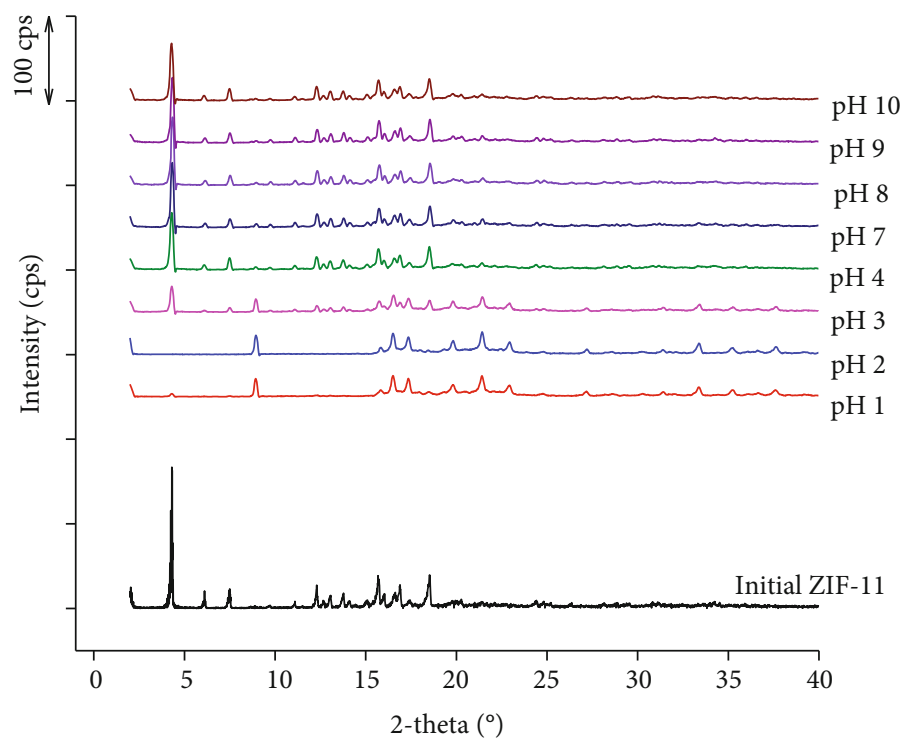

FIGURE 4: XRD patterns of ZIF-11 immersed in aqueous solutions with different pHs.

The surface area of zinc benzimidazolate is studied from its nitrogen adsorption/desorption isotherms (Table 1 and Figure 3). The material synthesized at 25 and $40^{\circ} \mathrm{C}$ exhibits the isothermal curves belonging to type I according to IUPAC classification and has a BET-specific surface area of 1066 and $347 \mathrm{~m}^{2} \cdot \mathrm{g}^{-1}$, respectively. The material synthesized at high temperature $\left(60\right.$ and $\left.100^{\circ} \mathrm{C}\right)$ or low temperature $\left(5\right.$ and $\left.15^{\circ} \mathrm{C}\right)$ possesses a very low BET-specific surface area $\left(2.2-8 \mathrm{~m}^{2} \cdot \mathrm{g}^{-1}\right)$. Since the gaps between the ZIF-11 particles synthesized at these temperatures are smaller than the kinetic diameter of nitrogen (3.0 against $3.6 \AA$ ) [13,20], the specific surface area of ZIF-11 calculated from nitrogen adsorption measurements is smaller than that of other members of ZIF family, such as ZIF-8 or ZIF-12 [21]. The ultrasonic-assisted hydrothermal process enhanced significantly the surface area of ZIF-11. It could explain by the fact that the acoustic cavitation force inducing a series of compressions and rarefactions in the molecules of the present solvent made highly dispersive and uniform ZIF-11 particles. The specific surface area of the obtained ZIF-11 $\left(1066 \mathrm{~m}^{2} \cdot \mathrm{g}^{-1}\right)$ is much higher than those synthesized with other procedures, for example, $745 \mathrm{~m}^{2} \cdot \mathrm{g}^{-1}$ (microwave heating) [17], $97 \mathrm{~m}^{2} \cdot \mathrm{g}^{-1}$ (ethanol solvent, room temperature) [21], and $350.29 \mathrm{~m}^{2} \cdot \mathrm{g}^{-1}$ (methanol solvent, room temperature) [15]. In addition, it is worth noting that the desorption line of ZIF-11 and composites does not form a loop at a low relative pressure $\left(P / P^{0}\right)$. Such shapes of isotherm curves have been observed for ZIF-11 in several previous publications [16]. This phenomenon may be due to the swelling effect, commonly observed in complex microporous materials with throats and cavities [22, 23].

The stability of ZIF-11 in the aqueous solution with various pHs is critical for the material's application. New peaks on the XRD patterns of ZIF-11 in the $\mathrm{pH}$ range of 13 indicate a change in the material structure, while the XRD patterns remain unchanged at higher $\mathrm{pHs}$ (Figure 4(b)). This fact implies that ZIF-11 is stable in the $\mathrm{pH}$ range of $4-10$.

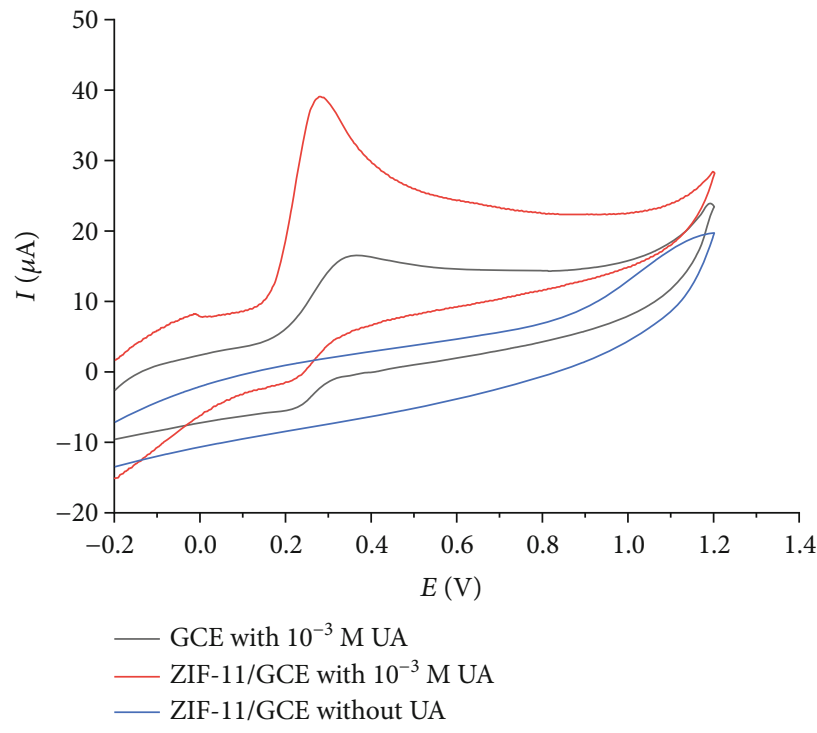

FIgURE 5: CV curves of UA on bare GCE and ZIF-11/GCE $\left(C_{U A}=10^{-3} \mathrm{M}\right.$ in $0.1 \mathrm{M}$ BRB solution, $\mathrm{pH}$ 7).

3.2. Voltammetric Determination of Uric Acid on ZIF-11Modified GCE

3.2.1. Cyclic Voltammetric Behavior of ZIF-11/GCE. A sharp peak on the CV curve obtained on ZIF-11/GCE is observed at a lower $E_{p}(0.28 \mathrm{~V})$ compared with an obtuse peak on bare GCE $\left(E_{p}=0.35 \mathrm{~V}\right)$ (Figure 5). In the buffer solution without UA, no redox peaks are observed on the ZIF-11/GCE, indicating that ZIF-11 is electrochemically inactive towards UA oxidation. The oxidation of UA on ZIF-11/GCE exhibits a higher current and a lower potential. The current value of the oxidation peak of UA on ZIF-11/GCE is approximately 


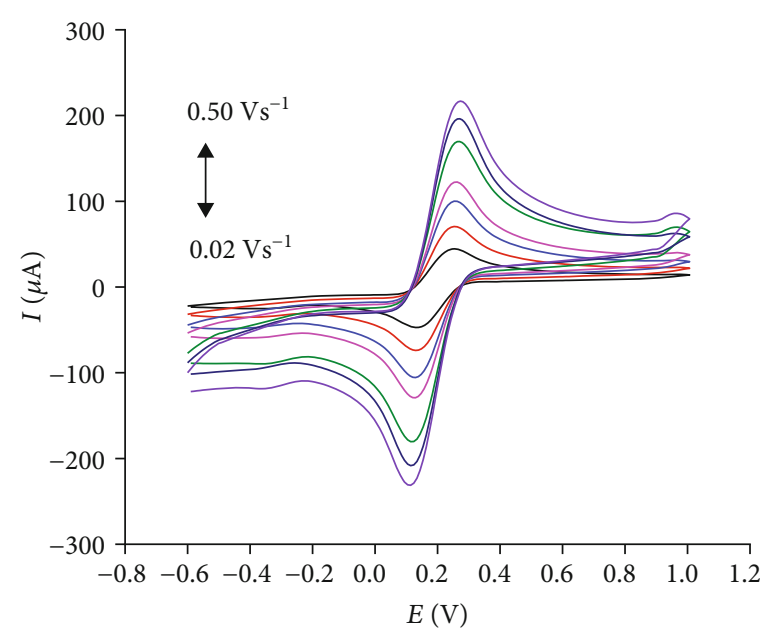

(a)

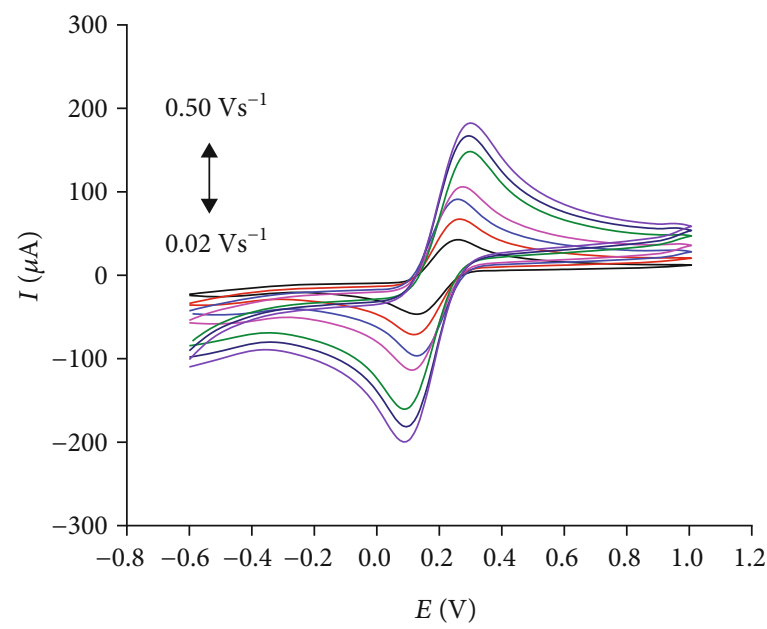

(c)

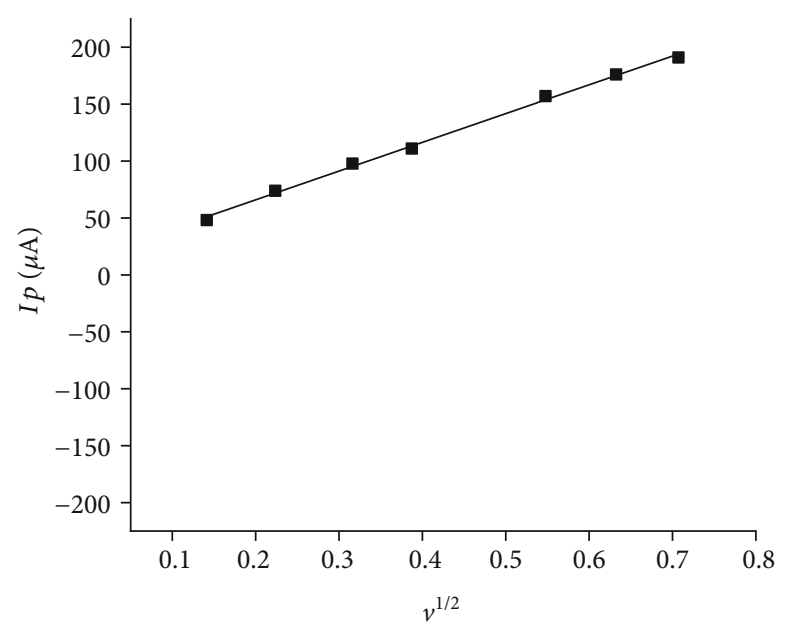

(b)

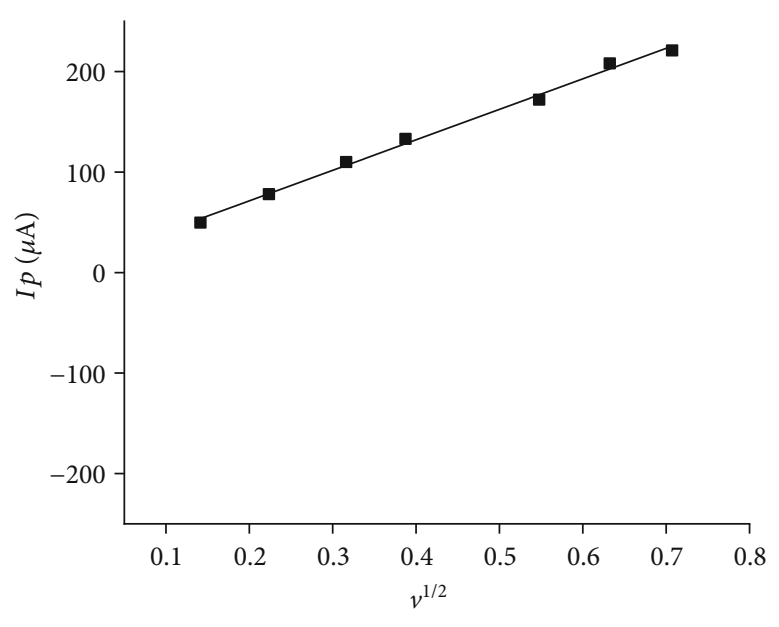

(d)

Figure 6: CV curves of $1 \mathrm{mM}\left[\mathrm{Fe}(\mathrm{CN})_{6}\right]^{3-/ 4-}$ on bare GCE $(\mathrm{a}, \mathrm{c})$ and ZIF-11/GCE (b, d) in $0.1 \mathrm{M}$ BRB solution, $\mathrm{pH} 7$.

2.2 times higher than that on GCE. This fact indicates that ZIF-11, as an electrode modifier, increases the number of adsorption sites and the active surface and thus enhancing the catalytic activity.

The electrochemically active surface of bare GCE and ZIF-11/GCE can be obtained from the Randles-Sevcik equation (1) [24].

$$
I_{p a}=\left(2.69 \times 10^{5}\right) \times n^{3 / 2} \times A \times D_{0}^{1 / 2} \times C \times v^{1 / 2},
$$

where $I_{p a}(\mu \mathrm{A})$ is the anodic peak current; $n$ is the number of electrons transferred in the oxidation and reduction process of the redox probe $(n=1) ; C$ is the concentration of $\left[\mathrm{Fe}(\mathrm{CN})_{6}\right]^{3-/ 4-} ; D$ is the diffusion coefficient $(7.6 \times$ $\left.10^{-6} \mathrm{~cm}^{2} \mathrm{~s}^{-1}\right)$.

The effective surface area could be obtained from the slope of $I_{p a}$ vs. $v^{1 / 2}$ linear plot. The linear equation is presented in equations (2) and (3) (Figure 6).

$$
\text { For bare GCE, } \begin{aligned}
I_{p a}= & (15.399 \pm 2.651)+(252.654 \pm 5.688) \\
& \times v^{\frac{1}{2}}, R=0.997,
\end{aligned}
$$

$$
\begin{aligned}
\text { For ZIF }-\frac{11}{\mathrm{GCE}}, I_{p a}= & (10.699 \pm 4.394)+(303.402 \pm 9.429) \\
& \times v^{\frac{1}{2}}, R=0.994 .
\end{aligned}
$$

The calculated effective surface area of ZIF-67/GCE $\left(0.082 \mathrm{~cm}^{2}\right)$ is higher than that of bare GCE $\left(0.068 \mathrm{~cm}^{2}\right)$, which is about 1.2 times.

(1) Effect of $p H$. The UA current peak shifts to a less positive potential as $\mathrm{pH}$ increases from 2 to 9 (Figure 7(a)), indicating that the reactions at the electrode are related to protons. The linear plot of the peak potential vs. $\mathrm{pH}$ is shown in Figure 7(b) (equation (4)). 


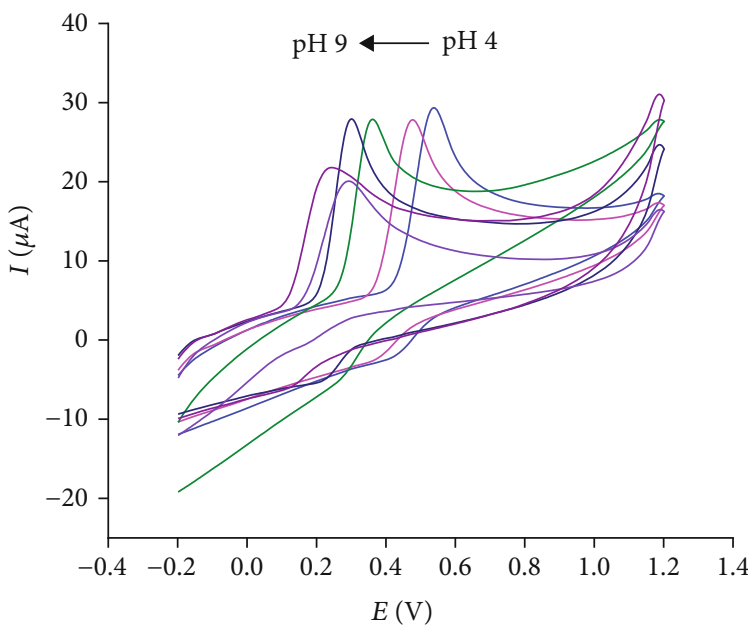

(a)

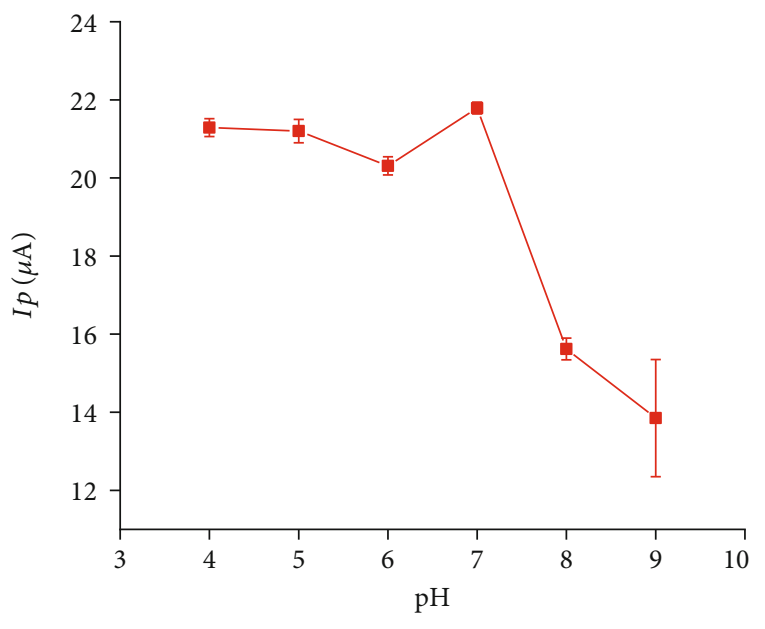

(c)

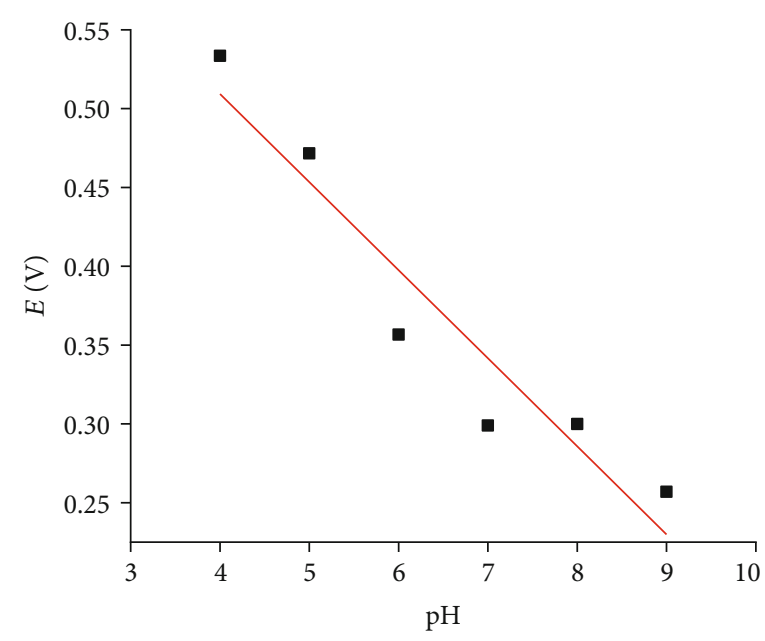

(b)

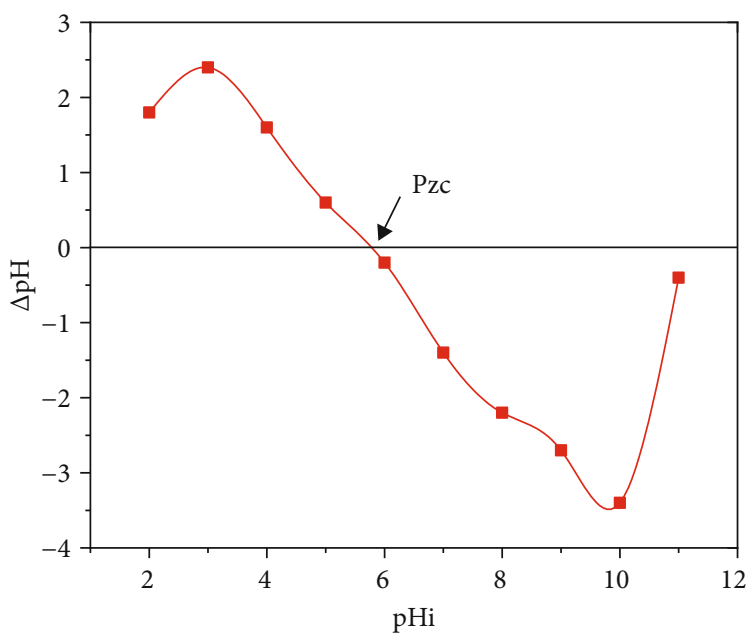

(d)

FIgURE 7: (a) CV curves of UA on ZIF-11/GCE with various pHs; (b) linear plot of $E_{p} \mathrm{vs} . \mathrm{pH}$; (c) plot of $I_{p}$ vs. $\mathrm{pH}\left(C_{U A}=10^{-3} \mathrm{M}\right.$ in $0.1 \mathrm{M}$ BRB solution, scan rate $50 \mathrm{mV} \cdot \mathrm{s}^{-1}$ ); (d) point of zero charge for ZIF-11.

$$
E_{p}=(0.73 \pm 0.06)+(-0.056 \pm 0.009) \times \mathrm{pH}, R=0.954
$$

The slope of this line (0.056) is close to the theoretical slope $(0.059 \mu \mathrm{A} / \mathrm{pH})$ of the Nernst equation. This fact indicates that the number of electrons and protons involved in the reaction is equal. Figure 7 (c) depicts that $\mathrm{pH}$ less than 7 seems to have little influence on the anodic peak current, but at higher $\mathrm{pH}$, the anodic peak current decreases. As we know that uric acid is a diprotic acid with $\mathrm{p} K_{\mathrm{a} 1}$ being 5.4 and $\mathrm{p} K_{\mathrm{a} 2}$ being 10.3 [25], at $\mathrm{pH}>5.4$, it exists as an anion (urate), and at $\mathrm{pH}<5.4$ , it exists in the neutral form. The point of zero charge (Pzc) for ZIF-11 estimated with the $\mathrm{pH}$ drift method is 5.8 (Figure $7(\mathrm{~d})$ ). When the $\mathrm{pH}$ of the buffer solution is less than 5.8 , the proton concentration has little influence on the anodic peak current. However, at $\mathrm{pH}$ greater than 5.8, the repulsion interaction between the urate and the negatively charged surface of ZIF-11 results in a decrease in the anodic peak current. The highest peak current is obtained at $\mathrm{pH} 7$ (Figure $7(\mathrm{~d})$ ), and therefore, this $\mathrm{pH}$ is selected for further experiments.

(2) Effect of Scan Rate. The kinetics of electrode reaction is investigated by using the peak current values of UA oxidation with scan rates from 0.1 to $0.5 \mathrm{~V} \cdot \mathrm{s}^{-1}$ (Figure $8(\mathrm{a})$ ). The anodic peak current, $I_{p a}$, varies linearly with $v^{1 / 2}$ according to equation (5)

$$
I_{p}=(-7 \pm 3)+(86 \pm 6) \times v^{\frac{1}{2}}, R=0.984
$$

The intercept varies from -10 to -4 , and it means that the line in Figure 8(b) does not pass the origin, indicating that the reactions on ZIF-11/GCE are controlled by diffusion $[26,27]$. 


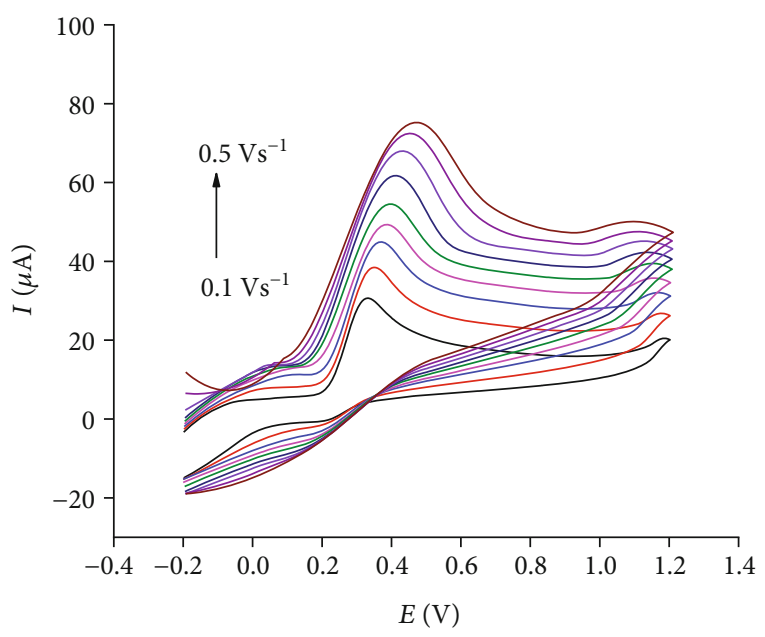

(a)

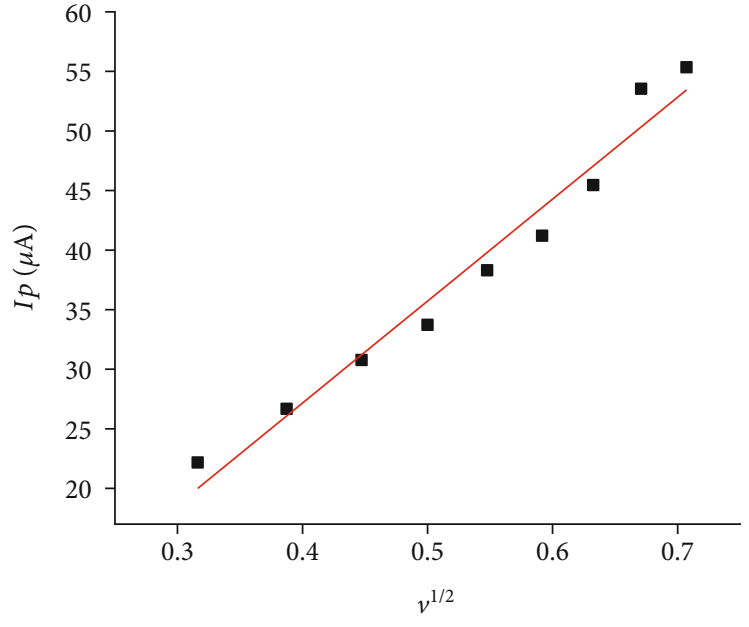

(b)

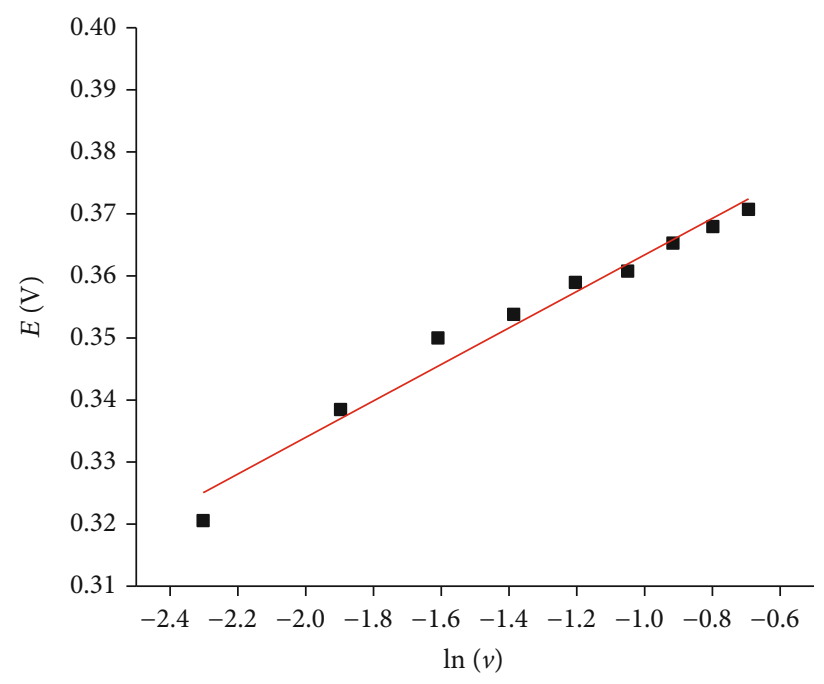

(c)

Figure 8: (a) CVs of UA on ZIF-11/GCE at various scan rates; (b) plot of $I_{p}$ vs. $v^{1 / 2}$; (c) plot of $E_{p}$ vs. $\ln (v), C_{U A}=10^{-3} \mathrm{M}$ in $0.1 \mathrm{M} \mathrm{BRBS}$ pH 7 .

For an irreversible system, the relationship between $E_{p}$ and $\ln v$ is described by the Laviron equation [28].

$$
\begin{aligned}
E_{p}= & E^{0}-\frac{R \times T}{(1-\alpha) \times n \times F} \ln \frac{R \times T \times K_{\mathrm{s}}}{(1-\alpha) \times n \times F} \\
& +\frac{R \times T}{(1-\alpha) \times n \times F} \times \ln v,
\end{aligned}
$$

where $R=8.314 \mathrm{Jmol}^{-1} \mathrm{~K}^{-1} ; T=298 \mathrm{~K} ; F=96500 \mathrm{Cmol}^{-1}$.

The linear plot of $E_{p}$ vs. $\ln (v)$ provides the value of $R \times$ $T /(1-\alpha) \times n \times F$. The influence of $\ln (v)$ on $E_{p}$ is expressed in equation (7) (Figure 8(c))

$$
E_{p}=(0.393 \pm 0.003)+(0.029 \pm 0.002) \times \ln (v), R=0.986 \text {. }
$$

For an irreversible system, the value of $\alpha$ is accepted as 0.5
[29], and when the value of $(1-\alpha) \times n$ is $0.89, n$ is found to be 1.77. Since an equal number of protons and electrons is involved in the reactions on the electrode, in this case, $n$ equal to 2 is acceptable. These results manifest that two electrons and two protons take part in the redox process of UA. A proposed oxidation mechanism of UA at ZIF-11/GCE is provided in Scheme 1.

3.2.2. Operational Parameters. Figure 9(a) indicates that the peak current of DP-ASV curves increases with the accumulation time up to 15 seconds, reaching a maximum, and then remains practically unchanged. This fact indicates that the accumulation of UA at the electrode surface reaches saturation. Accumulation potential has little influence on the peak current, probably because UA is almost neutral at $\mathrm{pH} 7$. Hence, accumulation on an open circuit is adopted. The accumulation potential with a low deviation $(-0.2 \mathrm{~V})$ (Figure 9(b)) and accumulation time (15 seconds) is selected for further experiments. 


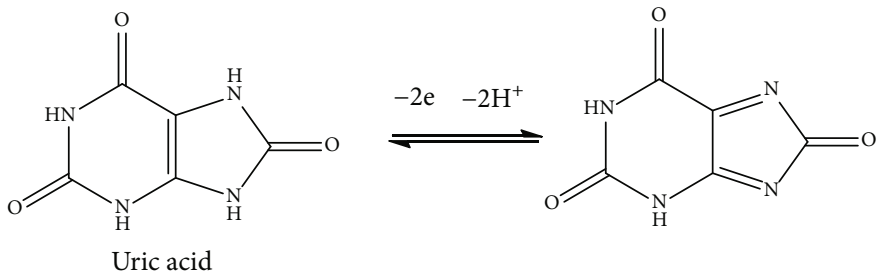

SCHeme 1: Mechanisms of UA oxidation.

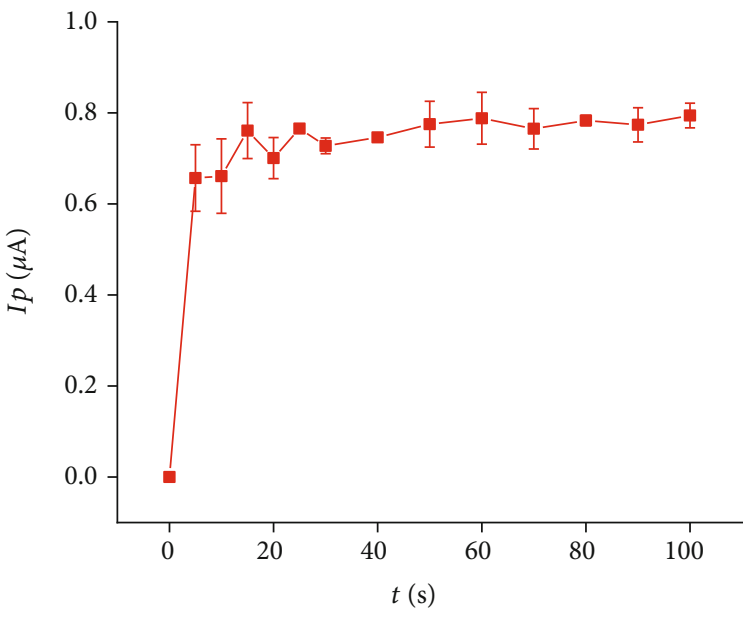

(a)

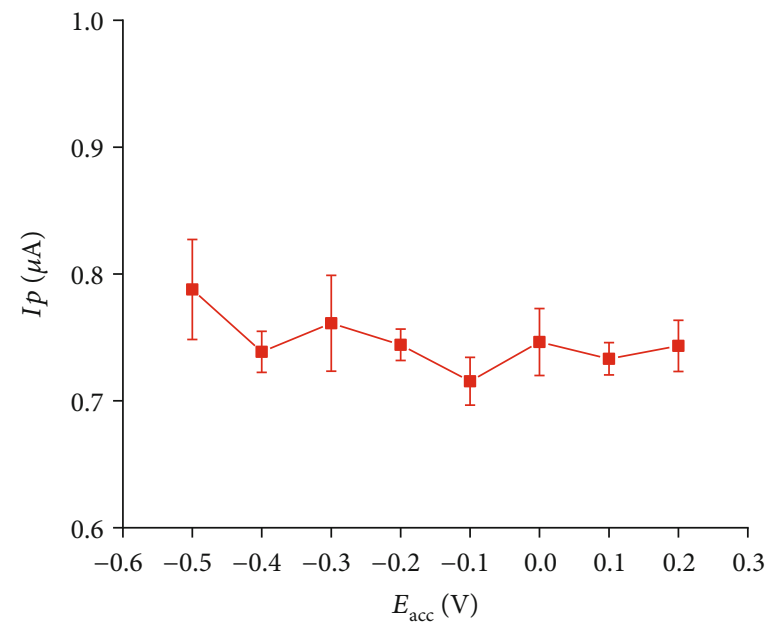

(b)

Figure 9: Plot of $I_{p}$ vs. accumulation time (a) and accumulation potential (b) when $C_{U A}=10^{-4} \mathrm{M}$ in $0.1 \mathrm{M}$ BRB solution, pH 7.

3.2.3. Repeatability, Reproducibility, Selectivity, and Limit of Detection. In the repeatability tests, DP-ASV curves are measured with three solutions containing 10,50 , and $100 \mu \mathrm{M}$ UA in four successive cycles (Figure 10). The relative standard deviation is acceptable as it is less than $1 / 2 \mathrm{RSD}_{H}\left(\mathrm{RSD}_{H}\right.$ is the relative standard deviation calculated for the Horwitz equation, $\mathrm{RSD}_{H}=2^{1-0,5 \lg C}$, where $C$ is the fraction concentration). The relative standard deviations (RSDs) of the current response are calculated to be $2.31 \%$ for $10 \mu \mathrm{M} U A, 2.24 \%$ for $50 \mu \mathrm{M} \mathrm{UA}$, and $1.00 \%$ for $100 \mu \mathrm{M} \mathrm{UA}$, which are less than $1 / 2 \mathrm{RSD}_{H}(7.40$, 5.81 , and 5.23, respectively). These results validate that the fabricated ZIF-11/GCE has acceptable repeatability.

The RSD (4.21\%) of 10 replicates is less than $1 / 2 \mathrm{RSD}_{H}$ (7.40\%), indicating that the proposed method possesses good reproducibility.

The selectivity of the ZIF-11/GCE is estimated by spiking possible interfering electroactive species coexisting in the real samples. In the present work, the tolerance limit $\left(C_{t l}\right)$ is considered as the concentration of the interferent that induces a relative error of $5 \%$ in the determination of $0.5 \mu \mathrm{M}$ UA. When the relative error of the detection peak current raised by an interferent is lower than $5 \%$, it is considered that this substance has no interference [30, 31]. According to this criterion, no interference is observed for the binary mixture composed of $0.5 \mu \mathrm{M}$ UA and glucose, ascorbic acid, sodium benzoate, saccharine (less $15 \mu \mathrm{M}$ or 30 -fold concentration), xanthine, hypoxanthine (less $10 \mu \mathrm{M}$ or 20 -fold concentration), $\mathrm{KCl}, \mathrm{Na}_{2} \mathrm{CO}_{3}, \mathrm{Na}_{2} \mathrm{SO}_{4}$, and $\mathrm{CaCO}_{3}(250.5 \mu \mathrm{M}$ or less 50-fold concentration) (Table 2). These results show that the present modified electrode has good anti-interference ability, which allows its further application in real biological samples.

Under optimal conditions, the DP-ASV technique is used to determine UA (Figure 11(a)). The $I_{p}$ increases linearly with the UA concentration in the range of $20-540 \mu \mathrm{M}$ (equation (8)).

$I_{p}=(-0.2000 \pm 0.0200)+(0.1742 \pm 0.0006) \times C ; R=0.999$

The sensitivity and LOD obtained as $3 S_{y / x} / b$ are $0.174 \mu \mathrm{A} \cdot \mu \mathrm{M}^{-1} \cdot \mathrm{cm}^{-2}$ and $0.48 \mu \mathrm{M}$, respectively (Figure 11(b)).

Table 3 compares the analytical performance of the proposed ZIF-11/GCE and some previously reported electrodes. The present electrode is comparable to or even better than the other electrodes. The obvious advantage is that the ZIF11 material is synthesized simpler than the composites with multiple components reported. ZIF-11/GCE exhibited better than some of the electrodes modified using pyrolytic graphite, uricase/carbon nanotube/carboxymethylcellulose, or ordered mesoporous carbon (OMC) functionalized with ferrocene carboxylic acid but failed to methylcellulose/graphene oxide/iron oxide nanohydrogel, zinc tetraaminophthalocyanine functionalized graphene nanosheets. 


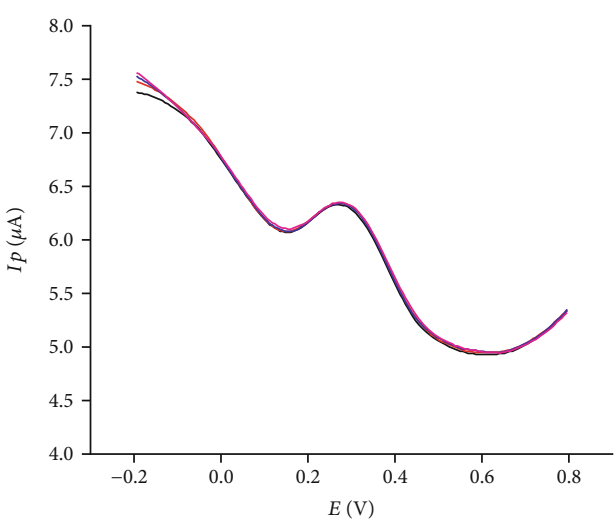

(a)

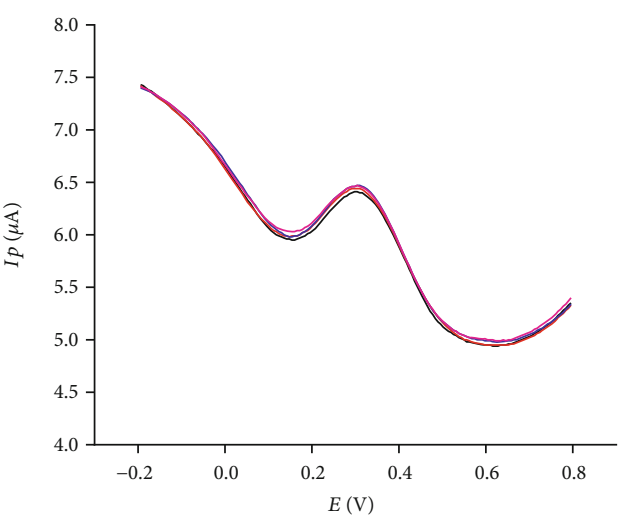

(b)

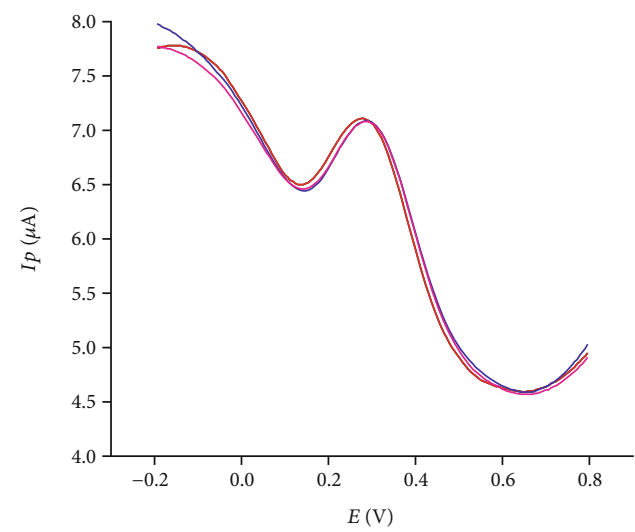

(c)

Figure 10: DP-ASV curves of UA at $10 \mu \mathrm{M}$ (a), $50 \mu \mathrm{M}$ (b), and $100 \mu \mathrm{M}$ (c).

TABLE 2: Tolerance limit of interferent $C_{U A}=0.5 \mu \mathrm{M}$ in $0.1 \mathrm{M} \mathrm{BRB}$ solution $\mathrm{pH}$, the mean value of $I_{p}(n=4)$.

\begin{tabular}{|c|c|c|c|}
\hline Interferents & $C_{t l}(\mu \mathrm{M})$ & $I_{p}$, mean $(\mathrm{m} \mu \mathrm{A})$ & $\mathrm{RE}(\%)$ \\
\hline \multirow{2}{*}{ Glucose } & 0 & 0.630 & 0.0 \\
\hline & 15 & 0.620 & -3.0 \\
\hline \multirow{2}{*}{ Ascorbic acid } & 0 & 0.535 & 0.0 \\
\hline & 15 & 0.558 & 4.3 \\
\hline \multirow{2}{*}{ Sodium benzoate } & 0 & 0.591 & 0.0 \\
\hline & 15 & 0.588 & -0.5 \\
\hline \multirow{2}{*}{ Saccharine } & 0 & 0.590 & 0.0 \\
\hline & 15 & 0.573 & -2.8 \\
\hline \multirow{2}{*}{ Xanthine } & 10 & 0.564 & 0.0 \\
\hline & 10 & 0.548 & -2.8 \\
\hline \multirow{2}{*}{ Hypoxanthine } & 10 & 0.602 & 0.0 \\
\hline & 10 & 0.628 & 4.2 \\
\hline \multirow{2}{*}{$\mathrm{KCl}$} & 0 & 1.183 & 0.0 \\
\hline & 25 & 1.138 & -3.8 \\
\hline \multirow{2}{*}{$\mathrm{Na}_{2} \mathrm{CO}_{3}$} & 0 & 0.619 & 0.0 \\
\hline & 25 & 0.599 & -3.2 \\
\hline \multirow{2}{*}{$\mathrm{Na}_{2} \mathrm{SO}_{4}$} & 0 & 0.590 & 0.0 \\
\hline & 25 & 0.583 & -1.2 \\
\hline \multirow{2}{*}{$\mathrm{CaCO}_{3}$} & 0 & 0.562 & 0.0 \\
\hline & 25 & 0.561 & -0.3 \\
\hline
\end{tabular}




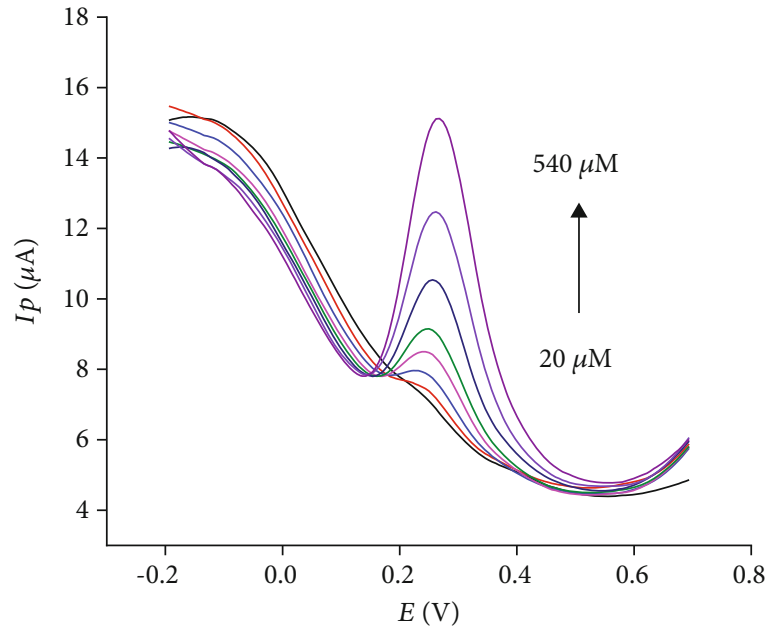

(a)

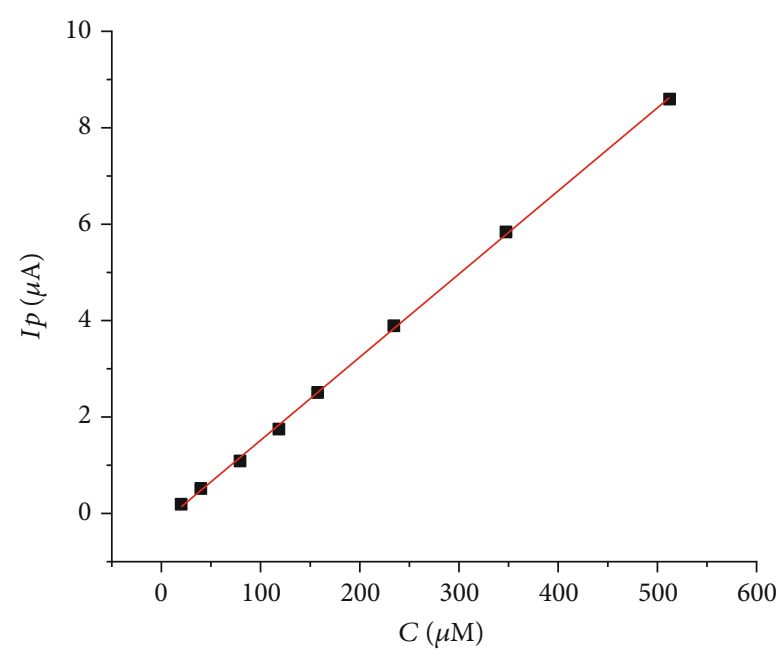

(b)

FIGURE 11: (a) DP-ASV curves of UA at ZIF-11/GCE at various UA concentrations; (b) Plot of $I_{p}$ vs. UA concentration.

TABLE 3: Comparison of the present with other modified electrodes.

\begin{tabular}{|c|c|c|c|c|}
\hline Modified electrode & $\begin{array}{l}\text { Linear } \\
\text { range }(\mu \mathrm{M})\end{array}$ & $\begin{array}{c}\text { Limit of } \\
\text { detection }(\mu \mathrm{M})\end{array}$ & $\begin{array}{l}\text { Sensitivity } \\
\left(\mu \mathrm{A} \cdot \mu \mathrm{M}^{-1} \cdot \mathrm{cm}^{-2}\right)\end{array}$ & Reference \\
\hline Methylcellulose/graphene oxide/iron oxide nanohydrogel/GCE & $0.5-140$ & 0.17 & 28.95 & {$[32]$} \\
\hline Zinc Tetraaminophthalocyanine functionalized graphene nanosheets/GCE & $0.5-100$ & 0.15 & 13.82 & [33] \\
\hline $\begin{array}{l}\text { Ordered mesoporous carbon (OMC) functionalized with ferrocene carboxylic } \\
\text { acid }\end{array}$ & $30-390$ & 1.8 & 0.317 & [8] \\
\hline Pyrolytic graphite activated electrode & $2.5-30$ & 1.4 & 7.700 & {$[34]$} \\
\hline Uricase-thionine-single-walled carbon nanotube modified electrode & $2-2000$ & 0.50 & 0.09 & {$[35]$} \\
\hline $\begin{array}{l}\text { Poly(brilliant green) and poly(thionine) modified carbon nanotube coated } \\
\text { carbon film electrode }\end{array}$ & $2-100$ & 0.6 & 0.248 & {$[36]$} \\
\hline Uricase/carbon nanotube /carboxymethylcellulose electrode & $20-5000$ & 2.8 & 0.233 & {$[9]$} \\
\hline ZIF-11/GCE & $50-540$ & 0.48 & 2.80 & $\begin{array}{c}\text { Present } \\
\text { work }\end{array}$ \\
\hline
\end{tabular}

TABLE 4: Recovery of the proposed method for UA determination in urine $(n=3)$.

\begin{tabular}{|c|c|c|c|c|}
\hline Sample & Spiked $(\mu \mathrm{M})$ & Found with DP-ASV ${ }^{\mathrm{a}}(\mu \mathrm{M})$ & Recovery (\%) & Found with HPLC \\
\hline \multirow{2}{*}{ Urine \#1 } & 0 & $22.518 \pm 1.757$ & & $22.506 \pm 0.132$ \\
\hline & 10 & $32.966 \pm 1.037$ & 104.48 & $35.943 \pm 0.293$ \\
\hline \multirow{2}{*}{ Urine \#2 } & 0 & $26.021 \pm 1.782$ & & $25.968 \pm 0.367$ \\
\hline & 10 & $35.837 \pm 3.580$ & 98.16 & $35.943 \pm 0.293$ \\
\hline \multirow{2}{*}{ Urine \#3 } & 0 & $28.462 \pm 1.001$ & & $28.410 \pm 0.737$ \\
\hline & 10 & $37.914 \pm 1.203$ & 94.52 & $38.053 \pm 0.483$ \\
\hline Paired- samples $t$-test & $t(5)=-1.05, p=0.342$ & $M=30.619 \pm 5.956$ & & $M=31.137 \pm 6.367$ \\
\hline
\end{tabular}

a: mean \pm standard deviation.

3.2.4. Real Sample Analysis. Three urine samples are analyzed by using the fabricated electrode, and the HPLC method is also used for the sake of comparison. The acceptable recovery of UA is 94.52 to $104.48 \%$. Besides, the paired samples $t$-test was performed to compare the analytical results between the proposed method and HPLC. There was no significant differ- ence in uric acid content for the results of DP-ASV analysis $(M=30.619 ; \mathrm{SD}=5.956)(M:$ mean; SD: Standard deviation $)$ and for HPLC analysis $(M=31.137$; SD $=6.367), t(5)=-$ $1.05, p=0.342$. These results indicate that ZIF-11/GCE can be effectively employed for the UA determination in real biological samples with excellent concurrent results (Table 4). 


\section{Conclusions}

The reaction temperature effects remarkably on the formation of the ZIF-11 phase. ZIF-11 materials could be obtained in a temperature range of about $25-40^{\circ} \mathrm{C}$. The zinc benzimimidazole synthesized out of this temperature range possesses the crystalline structure differing from the ZIF-11 phase and low specific surface area. A novel ZIF-11 modified GCE has been developed to determine UA. The UA oxidation is remarkably catalyzed with an increased peak current and a decreased overpotential. The determination was successively achieved at ZIF-11/GCE. The proposed method with good stability and reproducibility has been employed to the determination of UA in a real urine sample with acceptable results.

\section{Data Availability}

The data used to support the findings of this study are available from the corresponding author upon request.

\section{Conflicts of Interest}

The authors declare that they have no conflicts of interest.

\section{References}

[1] J. Hu, Q. Lu, C. Wu et al., "Germanium nanoparticles: intrinsic peroxidase-like catalytic activity and its biosensing application," Talanta, vol. 195, pp. 407-413, 2019.

[2] L. Li, J. Wang, and Z. Chen, "Colorimetric determination of uric acid based on the suppression of oxidative etching of silver nanoparticles by chloroauric acid," Microchimica Acta, vol. 187, no. 1, p. 18, 2020.

[3] A. Fang, Q. Wu, Q. Lu et al., "Upconversion ratiometric fluorescence and colorimetric dual-readout assay for uric acid," Biosensors \& Bioelectronics, vol. 86, pp. 664-670, 2016.

[4] X.-L. Li, G. Li, Y.-Z. Jiang et al., "Human nails metabolite analysis: a rapid and simple method for quantification of uric acid in human fingernail by high-performance liquid chromatography with UV-detection," Journal of Chromatography B, vol. 1002, pp. 394-398, 2015.

[5] Q. Li, S. Wei, D. Wu, C. Wen, and J. Zhou, "Urinary metabolomics study of patients with gout using gas chromatographymass spectrometry," BioMed Research International, vol. 2018, Article ID 3461572, 9 pages, 2018.

[6] W. Zheng, M. Zhao, W. Liu et al., "Electrochemical sensor based on molecularly imprinted polymer/reduced graphene oxide composite for simultaneous determination of uric acid and tyrosine," Journal of Electroanalytical Chemistry, vol. 813, pp. 75-82, 2018.

[7] S. S. Kumar, J. Mathiyarasu, and K. L. Phani, "Exploration of synergism between a polymer matrix and gold nanoparticles for selective determination of dopamine," Journal of Electroanalytical Chemistry, vol. 578, no. 1, pp. 95-103, 2005.

[8] J. C. Ndamanisha and L. Guo, "Electrochemical determination of uric acid at ordered mesoporous carbon functionalized with ferrocenecarboxylic acid-modified electrode," Biosensors \& Bioelectronics, vol. 23, no. 11, pp. 1680-1685, 2008.

[9] T. Fukuda, H. Muguruma, H. Iwasa et al., "Electrochemical determination of uric acid in urine and serum with uricase/- carbon nanotube /carboxymethylcellulose electrode," Analytical Biochemistry, vol. 590, article 113533, 2020.

[10] D. Li, M. Liu, Y. Zhan, Q. Su, Y. Zhang, and D. Zhang, "Electrodeposited poly (3, 4-ethylenedioxythiophene) doped with graphene oxide for the simultaneous voltammetric determination of ascorbic acid, dopamine and uric acid," Microchimica Acta, vol. 187, pp. 1-10, 2020.

[11] S. Krishnan, L. Tong, S. Liu, and R. Xing, "A mesoporous silver-doped $\mathrm{TiO} 2-\mathrm{SnO} 2$ nanocomposite on gC $3 \mathrm{~N} 4$ nanosheets and decorated with a hierarchical core- shell metalorganic framework for simultaneous voltammetric determination of ascorbic acid, dopamine and uric acid," Microchimica Acta, vol. 187, pp. 1-9, 2020.

[12] Q. Song, S. K. Nataraj, M. V. Roussenova et al., "Zeolitic imidazolate framework (ZIF-8) based polymer nanocomposite membranes for gas separation," Energy \& Environmental Science, vol. 5, no. 8, pp. 8359-8369, 2012.

[13] K. S. Park, Z. Ni, A. P. Cote et al., "Exceptional chemical and thermal stability of zeolitic imidazolate frameworks," Proceedings of the National Academy of Sciences, vol. 103, no. 27, pp. 10186-10191, 2006.

[14] E. M. Forman, A. Baniani, L. Fan et al., "Relationship between ethane and ethylene diffusion inside ZIF-11 crystals confined in polymers to form mixed-matrix membranes," Journal of Membrane Science, vol. 593, p. 117440, 2020.

[15] M. S. Boroglu and A. B. Yumru, "Gas separation performance of 6FDA-DAM-ZIF-11 mixed-matrix membranes for $\mathrm{H}_{2} / \mathrm{CH}_{4}$ and $\mathrm{CO}_{2} / \mathrm{CH}_{4}$ separation," Separation and Purification Technology, vol. 173, pp. 269-279, 2017.

[16] R. Chandra and M. Nath, "Facile synthesis of metal-organic framework (ZIF-11) and Ag NPs encapsulated-ZIF-11 composite as an effective heterogeneous catalyst for photodegradation of methylene blue," Applied Organometallic Chemistry, vol. 34, article e5951, 2020.

[17] J. M. Lucero, T. J. Self, and M. A. Carreon, "Synthesis of ZIF-11 crystals by microwave heating," New Journal of Chemistry, vol. 44, no. 9, pp. 3562-3565, 2020.

[18] A. V. Neimark, F.-X. Coudert, C. Triguero et al., "Structural transitions in MIL-53 (Cr): view from outside and inside," Langmuir, vol. 27, no. 8, pp. 4734-4741, 2011.

[19] N. A. Khan and S. H. Jhung, "Phase-transition and phaseselective synthesis of porous chromium-benzenedicarboxylates," Crystal Growth \& Design, vol. 10, no. 4, pp. 18601865, 2010.

[20] D. W. Breck, Zeolite Molecular Sieves, Wiley, New York, 1974.

[21] A. Noguera-Díaz, J. Villarroel-Rocha, V. P. Ting, N. Bimbo, K. Sapag, and T. J. Mays, "Flexible ZIFs: probing guest-induced flexibility with CO2, N2and Ar adsorption," Journal of Chemical Technology and Biotechnology, vol. 94, no. 12, pp. 37873792, 2019.

[22] S. Mondal, S. K. Kundu, and A. Bhaumik, "A facile approach for the synthesis of hydroxyl-rich microporous organic networks for efficient CO2capture and H2storage," Chemical Communications, vol. 53, no. 18, pp. 2752-2755, 2017.

[23] Y. Liao, J. Weber, B. M. Mills, Z. Ren, and C. F. J. Faul, "Highly efficient and reversible iodine capture in hexaphenylbenzenebased conjugated microporous polymers," Macromolecules, vol. 49, no. 17, pp. 6322-6333, 2016.

[24] N. F. Atta, S. A. Darwish, S. E. Khalil, and A. Galal, "Effect of surfactants on the voltammetric response and determination 
of an antihypertensive drug," Talanta, vol. 72, no. 4, pp. 14381445, 2007.

[25] C. L. Benn, P. Dua, R. Gurrell et al., "Physiology of hyperuricemia and urate-lowering treatments," Frontiers in Medicine, vol. 5, p. 160, 2018.

[26] R. T. Kachoosangi, G. G. Wildgoose, and R. G. Compton, "Sensitive adsorptive stripping voltammetric determination of paracetamol at multiwalled carbon nanotube modified basal plane pyrolytic graphite electrode," Analytica Chimica Acta, vol. 618, no. 1, pp. 54-60, 2008.

[27] J. Soleymani, M. Hasanzadeh, N. Shadjou et al., "A new kinetic-mechanistic approach to elucidate electrooxidation of doxorubicin hydrochloride in unprocessed human fluids using magnetic graphene based nanocomposite modified glassy carbon electrode," Materials Science and Engineering: C, vol. 61, pp. 638-650, 2016.

[28] E. Laviron, "General expression of the linear potential sweep voltammogram in the case of diffusionless electrochemical systems," Journal of Electroanalytical Chemistry and Interfacial Electrochemistry, vol. 101, no. 1, pp. 19-28, 1979.

[29] C. Li, "Electrochemical determination of dipyridamole at a carbon paste electrode using cetyltrimethyl ammonium bromide as enhancing element," Colloids and Surfaces B: Biointerfaces, vol. 55, no. 1, pp. 77-83, 2007.

[30] A. A. Ensafi, M. Taei, and T. Khayamian, "Simultaneous determination of ascorbic acid, epinephrine, and uric acid by differential pulse voltammetry using poly( $p s$ -xylenolsulfonephthalein) modified glassy carbon electrode," Colloids and Surfaces B: Biointerfaces, vol. 79, no. 2, pp. 480487, 2010.

[31] F. Xie, X. Lin, X. Wu, and Z. Xie, "Solid phase extraction of lead (II), copper (II), cadmium (II) and nickel (II) using gallic acid-modified silica gel prior to determination by flame atomic absorption spectrometry," Talanta, vol. 74, no. 4, pp. 836-843, 2008.

[32] E. Sohouli, E. M. Khosrowshahi, P. Radi, E. Naghian, M. Rahimi-Nasrabadi, and F. Ahmadi, "Electrochemical sensor based on modified methylcellulose by graphene oxide and $\mathrm{Fe} 3 \mathrm{O} 4$ nanoparticles: application in the analysis of uric acid content in urine," Journal of Electroanalytical Chemistry, vol. 877, article 114503, 2020.

[33] Y. Shi, L. Mei, J. Zhang et al., "Synthesis of zinc tetraaminophthalocyanine functionalized graphene nanosheets as an enhanced material for sensitive electrochemical determination of uric acid," Electroanalysis, vol. 32, no. 7, pp. 1507-1515, 2020.

[34] R. P. da Silva, A. W. O. Lima, and S. H. P. Serrano, "Simultaneous voltammetric detection of ascorbic acid, dopamine and uric acid using a pyrolytic graphite electrode modified into dopamine solution," Analytica Chimica Acta, vol. 612, no. 1, pp. 89-98, 2008.

[35] D. Chen, Q. Wang, J. Jin et al., "Low-potential detection of endogenous and physiological uric acid at uricase- thioninesingle-walled carbon nanotube modified electrodes," Analytical Chemistry, vol. 82, no. 6, pp. 2448-2455, 2010.

[36] M. E. Ghica and C. M. A. Brett, "Poly(brilliant green) and poly(thionine) modified carbon nanotube coated carbon film electrodes for glucose and uric acid biosensors," Talanta, vol. 130, pp. 198-206, 2014. 